\title{
Deficits in fine motor skills and their influence on persistence among gifted elementary school pupils
}

Gifted Education International 29(I) 28-42

(C) The Author(s) 2013 Reprints and permission: sagepub.co.uk/journalsPermissions.nav DOI: 10.II77/026I4294I2440649 gei.sagepub.com @SAGE

\section{Heidrun Stoeger}

University of Regensburg, Germany

\author{
Albert Ziegler \\ University of Erlangen-Nürnberg, Germany
}

\begin{abstract}
This article addresses the causes of underachievement in scholastic education. Whereas many studies have been able to show that motivational deficits provide an explanation for underachievement, little research has yet explored the possible influences of deficits in fine motor skills. The aim of our empirical study was, therefore, to investigate the influence of fine motor skills and how they may affect underachievement. We hypothesized that deficits in fine motor skills could possibly be mediated by persistence. The participants in this investigation were 53 gifted fourth-grade pupils ( 15 underachievers, 38 achievers) attending primary schools in Germany. In fact, underachievers and achievers could be differentiated on the basis of their fine motor skills and persistence levels. The differences attributed to persistence decreased when fine motor skills were statistically controlled.
\end{abstract}

\section{Keywords}

Underachievement, fine motor skills

\section{Corresponding author:}

Heidrun Stoeger, Chair for School Education, School Research, School Development, and Evaluation, University of Regensburg, Universitätsstr. 31, 93053 Regensburg, Germany

Email: heidrun.stoeger@paedagogik.uni-regensburg.de 


\section{Introduction}

In giftedness research, the phenomenon that gifted students are not able to exhaust their achievement potential is referred to as underachievement. Technically, underachievement is often defined as a discrepancy between an anticipated level of achievement on the basis of high cognitive abilities and a (significantly lower) level of achievement actually attained (for an overview refer to Peters et al., 2000; Reis and McCoach, 2000). An identification of underachievement emerges, in most cases, as the result of a comparison between intelligence values (measured with an intelligence test) and achievements (measured with grades awarded in school or through standardized scholastic aptitude tests). Should a significant discrepancy be evident between these figures, then the child is designated an underachiever. The degree of discrepancy considered to denote a case of underachievement is determined in different ways by different researchers. Several researchers adhere to a guideline by which gifted individuals are confirmed to be underachieving when their $z$-standardized cognitive abilities are at least one standard deviation higher than their $z$-standardized achievement ratings (Peters et al., 2000; Phillipson, 2008). In the research literature, depending on the definition of underachievement being used, up to $50 \%$ of gifted students have been diagnosed as underachievers (Phillipson, 2008; Rimm, 2003).

In recent decades, immense progress has been made in detecting the causes behind such discrepancies between cognitive abilities and scholastic achievement (for an overview refer to McCoach and Siegle, 2003; Peters et al., 2000; Reis and McCoach, 2000). Determinants considered to be of particular interest include motivational deficits, underdeveloped learning and work skills, inadequate control convictions, poor ability self-concepts, developmental factors, chance, personality parameters, environmental factors (e.g., occupational stereotypes, gender role convictions), and the detrimental influences exercised by socialization agents such as parents, teachers, and the media.

Several of the studies in the field applied qualitative clinical or single-subject research methods. There were, however, a number of quantitative studies that investigated whether or not the variables detected in previous studies do actually differentiate between achievers and underachievers. For instance, McCoach and Siegle (2003) were able to show that the 56 gifted underachievers in their sample could be differentiated from the 122 gifted achievers with regard to general academic self-perceptions, attitudes towards school, attitudes towards teachers, motivation and self-regulation, as well as goal valuation.

With the help of a logistic regression analysis, they were able to correctly classify more than $81 \%$ of their test subjects as either gifted achievers or gifted underachievers. The extremely promising results of this and other studies have contributed to a better general understanding of the phenomenon of underachievement and are currently being applied in practice as the basis of a wide assortment of approaches to reduce and eliminate underachievement.

Future research can, above all, focus on two directions. Firstly, attempts should be taken to examine whether the list of variables proposing to explain underachievement is exhaustive. For example, there are indications that fine motor deficits can play a 
significant role in the emergence of underachievement, a perspective which has not received considerable attention by either practitioners or researchers in the past.

Secondly, in future research the relationships among the various explanatory variables of underachievement should be subjected to more precise examination. Should the interrelationships among these variables not be explicitly investigated, then one would be left with the impression that the individual variables determined to explain underachievement exert an additive impact on its materialization. In fact, other sorts of relationships seem to be plausible. In the following, we will first provide an overview of empirical findings which indicate that fine motor skills could actually contribute to the explanation of how underachievement comes into being. Subsequently, we will discuss how a possible relationship between different causes of underachievement may be characterized. We will solidify these considerations for the proposed relationship between fine motor skill deficits and persistence.

\section{The influence of fine motor skills on learning and achievement}

In the research literature, one finds several indications that fine motor skills can exercise an indirect as well as a direct influence on learning behaviours and achievement behaviours. The fine coordination of small muscle groups, above all those in the hand, is essential for a wide variety of activities which are significant for (scholastic) learning. Among these are holding and guiding writing instruments and paintbrushes, using rulers and scissors, turning the pages of a book and placing the pieces of a puzzle together properly (Cantell et al., 1994; Losse et al., 1991). Also, correlations have been confirmed to exist between fine motor skills and specific cognitive abilities such as optical differentiation, reaction speed (Voelcker-Rehage, 2005), and intelligence (Wassenberg et al., 2005). These in turn influence learning and achievement behaviour.

As these findings would lead one to expect, correlations have been isolated between fine motor skills and achievement. Vacc et al. (1987), for instance, were able to show that among children in kindergarten, fine motor skills were the best predictors of performance on standardized achievement tests administered later (in first grade). In their longitudinal study with children in kindergarten in first grade, Luo et al. (2007) found that fine motor skills were able to predict later mathematical abilities. Further studies confirmed correlations between fine motor skills and scholastic achievement up through, and to the end of, primary school (e.g., Baedke, 1980; Beilei et al., 2002).

One may also presume that these relationships are maintained over a longer period of time. One argument to support this position would be the fact that fine motor skills are important for the development and attainment of several of the abilities required in the scholastic environment and that these abilities do not by any means lessen in significance for learning and achievement behaviour in later stages of schooling (see Graham, 1990; Graham and Weintraub, 1996). Counted among these are writing speed, quality and frequency of written activities, and the willingness to rework previously written material. None of these skills have yet been subjected to a great deal of attention by giftedness research. Only in the Munich Dynamic Model of Giftedness, developed by Ziegler and 
Perleth (1997), is it presumed - in accordance with work published by Ackerman (1987, 1992) - that fine motor skills have an influence on performance development.

However, the authors situate the point at which the influence exerted by fine motor skills materializes, which happens at a relatively late stage of development, shortly before the achievement asymptote of a talent domain is to be attained. The findings reported above on the significance of fine motor skills in school do, however, indicate that these skills could - also among gifted students - very well be important for performance development at a much earlier stage of development. Fine motor deficits could, therefore, contribute to an explanation of the phenomenon of underachievement among gifted children.

The first indications leading to this assumption were provided by two empirical investigations conducted with fourth graders (Stoeger et al., 2008; Ziegler et al., 2008). In both studies, gifted underachievers could be significantly differentiated from gifted achievers on the basis of their fine motor skills. With the assistance of a logistic regression analysis, Stoeger et al. (2008) were further able to demonstrate that the interaction term formed between fine motor skills and concentration could predict group membership for underachievers. More than $83 \%$ of the gifted students could, on the basis of this analysis, be correctly classified as either achievers or underachievers. These findings expanded the list of potential explanatory variables for the phenomenon of underachievement to include fine motor skills.

\section{The relationship between several causal variables associated with underachievement}

No full account of how the relationship between the various causal factors of underachievement takes form has yet been advanced. Often, it is implicitly assumed that the various causal factors exert an additive influence. At least that is what one is left to presume from the lists of previously determined causes for underachievement, which are regularly published in literature on the topic. There are, however, other plausible relationships, For instance, the causes of underachievement may interact in a compensatory manner, they may reciprocally reinforce each other, or hierarchical relationships could exist.

Such relationships have already been identified in the area of learning and achievement research, for instance between intelligence and effort. Low intelligence can be counterbalanced by a particularly high degree of effort (Ditton, 1998). In the case of underachievement, a compensatory relationship could, for instance, exist in situations where motivational deficits and test anxieties are simultaneously present (Ziegler and Stoeger, 2004). Although motivational deficits (as a causal factor for underachievement) normally result in a child spending less time learning and studying, test anxiety might (as a second causal factor for underachievement) lead to an increase in time invested in learning and studying in order to avoid a threat to self-esteem produced by poor performance.

A well-known example of the reciprocal reinforcement of effects among various causal factors in the area of learning would be the so-called talent-environment interactions (Plomin, 1994; Scarr and McCartney, 1983). One example of such interactions would be 
when a child who demonstrates giftedness in the domain of music is given access to special learning and practice opportunities on the basis of these talents. In the case of underachievement, a reciprocally reinforcing effect among causal factors would then exist when motivational deficits (causal factor 1) lead to the utilization of superficial learning strategies (causal factor 2) and these - mediated through poor achievement rates - would, in turn, contribute to a reduction in motivation.

A further type of relationship among the causes of underachievement would be a hierarchical one. For instance, one can well imagine that culture or social environment may influence how scholastic encouragement is approached at home. This, in turn, can have consequences for scholastic motivation, learning behaviour and fine motor skills among gifted children, which, in combination, contribute to underachievement.

One can conceive of several direct effects that deficits in fine motor skills could have on underachievement. For example, when taking tests which are limited in time, pupils with deficits in fine motor skills may consistently have difficulties finishing on time. Their written responses when working through exercises may also be so illegible that the teacher cannot decipher enough of what is written to properly evaluate the exercises or exam. Although these assumptions must, of course, be first empirically clarified, we expect that the most powerful effects of fine motor skills on inducing underachievement come into effect only in combination with other factors. For instance, there are several indications that the relationship between fine motor skills and concentration cited in Stoeger et al. (2008) is of a hierarchical nature.

Gifted children who demonstrate fine motor skill deficits must permanently switch their attention back and forth between their hand movements and the task they are working on. As a result, they lack the full attention that they need to resolve the task at hand. These shortfalls in attention are, in effect, induced by their deficits in fine motor skills (Christensen 2004, 2005; Graham, 1990; Scardamalia et al., 1982).

In addition to a direct effect and a hierarchical relationship with attention, there are a number of further ways in which deficits in fine motor skills could conceivably exert an influence over the development of underachievement. As such, it seems plausible that they could have a negative influence on motivation. Motivation itself - as the research literature makes undeniably clear - makes a significant contribution to the explanation of how underachievement may develop (see McCoach and Siegel, 2003; Peters et al., 2000; Reis and McCoach, 2000). Of particular interest to us is the construct of persistence.

A hierarchical relationship could also exist between deficits in fine motor skills and persistence. It is highly possible that pupils with deficits in fine motor skills may - above all on tasks which require a high demand on fine motor skills, for example writing or drawing - demonstrate lower levels of persistence, eventually resulting in underachievement. Unfortunately, to the best of our knowledge, only one study has been published which draws a reference to concepts related to this hypothesis. In an investigation conducted by Losse et al. (1991), pupils with fine motor deficits showed increased tendencies for irritable behaviour and resigned depressive dispositions. Regrettably, this study did not take a closer look at persistence among pupils, and no clarifications were sought as to whether these negative motivational outcomes - prompted by deficits in fine motor skills - may have had detrimental effects on achievement and potentially provoked underachievement. 
For these reasons, in our study we will first examine whether achievers and underachievers can be differentiated regarding their fine motor skills and persistence, and if differences found in persistence levels can, in effect, be attributed to fine motor skill deficits.

\section{Aims of the study and hypotheses}

The first objective of this study was to replicate the results pertaining to fine motor skills obtained by Stoeger et al. (2008) and Ziegler et al. (2008). However, we chose to assess fine motor skills with an instrument that more closely represented the demands children are expected to meet in scholastic environments. Furthermore, the relationship between two variables to which underachievement can be attributed, namely fine motor skill deficits and persistence, was to be examined more closely. We presumed that the relationship would be hierarchical, that is, that the effects pertaining to underachievement caused by deficits in fine motor skills are mediated by persistence.

In our empirical study, we examined five hypotheses. The first two hypotheses correspond to the construct of underachievement and simply denote a replication of earlier findings. The last three hypotheses correspond to the relationships inherent among fine motor skills, persistence and underachievement.

\section{Hypothesis I: Scholastic achievement is correlated with cognitive abilities}

Several empirical investigations and meta-analyses have demonstrated that cognitive abilities are closely correlated to scholastic achievement (Fraser et al., 1987; Kühn, 1987; Wang et al., 1993). This hypothesis addresses an essential prerequisite for the construct of underachievement.

\section{Hypothesis 2: Some pupils with high IQs do, however, demonstrate substantial differences regarding their achievement levels}

On the basis of the definition of the concept of underachievement (Reis and McCoach, 2000) and previous research findings (for an overview refer to Peters et al., 2000; Reis and McCoach, 2000), one can presume that we will also encounter the phenomenon of underachievement in our sample.

\section{Hypothesis 3: Underachievers can be differentiated from achievers with regard to fine motor skills}

The studies conducted by Stoeger et al. (2008) and Ziegler et al. (2008) were able to produce the first indications that the fine motor skills that underachievers have at their disposal are less well developed than those available to achievers, and that underachievement can be predicted on the basis of these deficits in fine motor skills. 


\section{Hypothesis 4: Underachievers can be differentiated from achievers with regard to persistence}

A large number of studies have shown that underachievers demonstrate less advantageous motivational patterns than achievers (McCoach and Siegel, 2003; Reis and McCoach, 2003). These findings can be confirmed in conjunction with a wide variety of motivational variables, including, among others, persistence (Ryneri et al., 2003; Sovik et al., 1994). Based on these findings, we presume that underachievers will show poorer persistence levels than achievers.

\section{Hypothesis 5: The differences between underachievers and achievers in persistence postulated in Hypothesis 4 can be attributed, in part, to differences in fine motor skills}

Particularly for tasks that call for well-developed fine motor skills (e.g., writing, drawing), one can expect that pupils demonstrating fine motor skill deficits will also exhibit lower levels of persistence. The first evidence of this relationship was supplied by investigations conducted by Losse et al. (1991). They were able to confirm that certain emotional effects, which can be associated with deficits in fine motor skills, are, in turn, significant for scholastic motivation. On account of these findings, one may venture to say that differences in persistence found to exist between underachievers and achievers are, at least in part, to be attributed to deficits in fine motor skills.

\section{Method}

\section{Participants}

A total of 307 pupils in the fourth grade from 15 classes attending six different primary schools took part in the investigation. The mean age of the participants was 10.48 years $(\mathrm{SD}=0.40$ years; range $=8.83-11.25$ years $)$. There was no significant age difference between the girls and boys. In order to assess cognitive abilities, each pupil completed a German version of the Culture Fair Intelligence Test (CFT). Reported here are - with the exception of the results to Hypothesis 1 - mainly those results obtained from the pupils who, according to Gordon and Bridglall (2005), can be considered gifted, i.e. those who, in accordance with the reference values of the CFT, were among the top $15 \%$. In our sample, this came to a total of 53 pupils (23 girls, 30 boys).

In the following, we will use the term underachiever to refer to those pupils whose $z$ standardized average scholastic performance across all subjects recorded on their midterm report cards was at least one standard deviation below their $z$-standardized result on the intelligence test. Among the 53 gifted pupils identified, 15 were found to be underachievers according to this criterion, and of these 11 were male and four were female. Among the 38 achievers, 19 were male and 19 were female. 


\section{Measuring instruments}

Cognitive abilities. The cognitive abilities of the pupils were assessed with the assistance of the German version (Weiss, 2006) of the CFT (Catell, 1960). The test, which is presented in a paper-and-pencil format, takes about 30 minutes to complete and demands only minor verbal competence. Validation studies conducted with standardization samples composed of German schoolchildren show that this test is compliant with established quality criteria concerning measuring methodology.

Fine motor skills. In order to assess their fine motor skills, the pupils were asked to reproduce written passages from a text, a measure that is often described in the research literature (Baedke, 1980) to measure visual-motor integration. The children were each presented with a copy of the text on a single sheet of paper and a blank sheet on which to reproduce it. To ensure that the children did not start reading the text before the start of the test, the sheets were placed face down on their desks. The investigators leading the session gave the following instructions verbally:

On the sheet of paper in front of you there is a text, and you will have exactly three minutes to reproduce it on the blank sheet of paper. Please do not read through the text beforehand, but start copying it right away. It is important that you work as quickly as possible, but at the same time you should be as careful and neat as possible. When I say 'stop', please put your pencils down. Turn over your sheets now; you may begin working at once.

The investigator used a stopwatch to time the test. The total number of syllables reproduced from the text served as a measure of fine motor skills.

Persistence. To obtain a measurement of persistence, the children were asked to reproduce visual patterns shown to them. Each child received a DINA4-standardized sheet of paper containing 11 rows of geometrical patterns, a sheet of paper containing items from the $\mathrm{d} 2$ test (a test to assess attention developed by Brickenkamp, 1962), a blank sheet of paper (also in DINA4 format) and a sharpened pencil. The sheet of paper with the $\mathrm{d} 2$ items served merely as an alternative task, should the children no longer want to continue reproducing the patterns from the other sheet. The instructions provided by the investigator were as follows:

Please take the sheet of paper on which you see different patterns and place it directly next to the blank sheet of paper so that the little arrow is pointing up. Please draw all the patterns, one after the other, in the same order in which you see them on the paper. Start with the figure on the left-hand side on the top of the paper, the one with the little arrow pointing to it. Then draw all the figures moving from left to right. Begin with the first row, and then go on to the second row, and then the third, etc. You may continue drawing these figures for as long as you want to. When you don't want to draw any more patterns, then work on the other sheet of paper with the letters on it. On this paper you should try to find all of the d's with two dashes around them. This means you should mark all of the d's that have two 
Table I. Intercorrelations, means and standard deviations among all measures.

\begin{tabular}{lcccc}
\hline & $(2)$ & $(3)$ & $(4)$ & Mean (SD) \\
\hline $\begin{array}{c}\text { (I) Intelligence (raw scores on } \\
\text { the short form of the CFT) }\end{array}$ & $-0.42^{\mathrm{b}}$ & -0.14 & $-0.26^{\mathrm{a}}$ & $70.89(3.35)$ \\
$\begin{array}{c}\text { (2) Scholastic achievements } \\
\text { (average report card grades) }\end{array}$ & & $-0.46^{\mathrm{c}}$ & $-0.35^{\mathrm{a}}$ & $1.98(0.4 \mathrm{I})$ \\
$\begin{array}{l}\text { (3) Fine motor skills (number of } \\
\text { syllables reproduced) }\end{array}$ & & 0.23 & $50.71(16.72)$ \\
$\begin{array}{l}\text { (4) Persistence (number of } \\
\text { patterns reproduced) }\end{array}$ & & & $71.86(42.28)$ \\
\hline
\end{tabular}

${ }^{a} p<0.05$. ${ }^{b} p<0.01 .{ }^{c} p<0.001$. Sample size was 53 . Grades are scaled inversely.

dashes above them, two dashes below them, or one dash above and one dash below them. Here you should start at the upper left-hand corner and work down through to the bottom.

The investigators were informed that on this second test, in contrast to the original, speed was not an issue. In assessing persistence, note was made of the total number of patterns reproduced.

Scholastic grades. The classroom teachers supplied us with the report card grades their students were awarded across all classes. Here one should note that the grade scale in Germany ranges from one to six, whereby one represents the best grade possible and six the poorest.

\section{Data collection}

The persistence test, the fine motor skills tests, and the cognitive ability test were administered to the pupils in the second semester of the school year, during regular classroom instruction. The survey, including a short introduction, took about one hour to complete. The investigation was conducted by specially trained school psychologists.

\section{Results}

The following section first offers a review of the descriptive statistics calculated for the variables. This will be followed by a presentation of the results concerning our five hypotheses. Means, standard deviations and intercorrelations among all measures are presented in Table 1. The absolute value of the correlations calculated between the four measures range from 0.14 to 0.46 .

On the basis of a wide variety of investigative findings, in Hypothesis 1 it was presumed that scholastic achievement and intelligence would correlate positively. This hypothesis could be confirmed. As expected, the results of the CFT showed a significant correlation of $r=0.42(p<0.01)$ with the mean grade point averages obtained, across all courses, on mid-term report cards. Pupils with higher cognitive abilities demonstrated better scholastic achievement rates. 
In Hypothesis 2, the assumption was made that the phenomenon of underachievement would also be evident in our sample. This was in fact the case. The subsample of underachievers, defined in accordance with our criterion, did actually show significantly poorer mean achievement rates than the achievers (underachievers: mean $=2.43$, $\mathrm{SD}=0.31$; achievers: mean $=1.79, \mathrm{SD}=0.29 ; t(51)=-7.09, p<0.001)$. Interestingly, the underachievers demonstrated higher cognitive abilities than the achievers (raw scores on the short form of the CFT: underachievers: mean $=72.27, \mathrm{SD}=2.89$; achievers: mean $=70.13, \mathrm{SD}=3.39 ; t(51)=2.15, p<0.05)$. For this reason, in the analysis of the following hypotheses, cognitive abilities are partialled out. As this covariate did not demonstrate statistical significance at any point in further analytical processes, it will not be mentioned in the following report.

Hypothesis 3 made the prediction that underachievers could be differentiated from achievers on the basis of their fine motor skills. This hypothesis was validated. The underachievers in our sample showed poorer results on the fine motor test (number of syllables reproduced: underachievers: mean $=37.6, \mathrm{SD}=10.07$; achievers: mean $\left.=54.66, \mathrm{SD}=16.29 ; F(1,50)=11.76, p<0.01, \eta^{2}=0.19\right)$.

Hypothesis 4 anticipated a clear distinction between underachievers and achievers with regard to persistence. This hypothesis was also substantiated. The underachievers in our sample showed evidence of lower persistence levels than the achievers (number of patterns reproduced: underachievers: mean $=44.67, \mathrm{SD}=35.42$; achievers: mean $\left.=84.63, \mathrm{SD}=44.30 ; F(1,50)=7.10, p<0.05, \eta^{2}=0.12\right)$.

Hypothesis 5 predicted that the differences in persistence between underachievers and achievers in our sample could be reduced if fine motor skills were to be controlled statistically. In order to investigate this assumption, fine motor skills were treated as a covariate in the analysis. A direct result of partialling fine motor skills out of the relationship was that the significance of the differences between underachievers and achievers did, in fact, decrease (from $F(1,50)=7.10, p=0.01$ to $F(1,50)=4.16, p=0.05$ ) and the effect size diminished (from $\eta^{2}=0.12$ to $\eta^{2}=0.08$ ) by one-third.

\section{Discussion and implications for practice}

Research on the topic of underachievement has shown immense progress in recent decades (see McCoach and Siegle, 2003). With our study, we would like to contribute to these advances on two levels. In the first place, the investigation of fine motor skills opens analysis of a variable, to this point widely ignored, which could potentially explain the origin of underachievement. In the second place, the relationship between fine motor skills and the motivation response persistence - another variable which has been widely discussed as an explanatory factor in underachievement - was analysed. In that the relationship between variables accepted as factors contributing to underachievement has not previously generated a great deal of attention, this approach presents the field with an expansion of certain directions which were previously poorly investigated.

The results of our study can be summarized as follows. Hypotheses 1 and 2 addressed the phenomenon of underachievement directly and could be confirmed. As expected, pupils with higher levels of cognitive abilities showed better scholastic performances in our study (Hypothesis 1). Underachievers in our sample showed, as anticipated, poorer 
grades although their cognitive ability levels proved to be even higher than those measured among the achievers (Hypothesis 2). This unexpected finding makes their poorer scholastic achievement levels even more problematic. Interventions as well as preventative measures appear to be all the more imperative.

Hypotheses 3, 4, and 5 were also confirmed. As anticipated on the basis of our preliminary considerations, underachievers demonstrated poorer fine motor skills (Hypothesis 3 ) and lower levels of persistence than achievers (Hypothesis 4). Of particular interest was the relationship proven to exist between fine motor skills and persistence. As presumed in Hypothesis 5, differences between underachievers and achievers in persistence could be significantly reduced after fine motor skills were statistically controlled.

The findings reported above suggest a variety of implications for the educational process. First, deficits in fine motor skills can affect achievement negatively. In particular, they might play a role in causing an individual to underachieve. Therefore, preventions and interventions of underachievement should take them into consideration. Should this not be the case, achievement deficits might accumulate. In addition to the direct effects that deficits in fine motor skills have on achievement (Graham, 1990; Graham and Weintraub, 1996) one may also expect indirect effects. Besides the effects examined in Stoeger et al. (2008) concerning attention and the effects concerning persistence described in this study, additional implications can be expected. For example, the quality of a pupil's handwriting has an impact on how teachers assess scholastic proficiency (see SweedlerBrown, 1992) as well as on performance evaluations (e.g. Briggs, 1980; Chase, 1986; Hughes et al., 1983). As the assessments made by teachers of proficiency and performance have a great deal of influence on scholastic self-concepts, the quality of a pupil's handwriting also mediates, via the mechanism described here, an influence on a child's self-concepts of her or his. The first indications of this relationship were reported by Piek et al. (2006).

Second, in future efforts to identify gifted schoolchildren, care should be given to utilize measuring instruments which place little demand on fine motor skills. For example, the implementation of speed tests to measure cognitive abilities would overlook a segment of pupils with deficits in fine motor skills and the type II error would be raised. Also, various tests of creativity, which for example call for the applicant to draw patterns or pictures, can be said to discriminate against schoolchildren with deficits in fine motor skills. Here, once again, we are faced with the risk of aggravating a type II error.

Third, several giftedness programmes require applicants to demonstrate fine motor skills. These include, for instance, measures that integrate writing, drawing or painting into their curricula. The full benefits of such concepts, however, would not be attained among children with deficits in fine motor skills. For this reason, the proportion of measures which call for fine motor skills should either be reduced or pupils with deficits in fine motor skills should be given access to a special intervention aimed at reducing these deficits prior to participation in such programmes.

Our study provides a number of ideas upon which future research can be based. First, to the best of our knowledge, no suitable standardized test of fine motor skills has yet been published. Most researchers rely on a series of tasks and exercises, without the benefit of having access to a predefined, precisely structured set of specifications. As there is an ever increasing body of knowledge pointing to the high significance fine motor skills 
seem to have for academic performance, more attention should be afforded to their assessment and diagnosis. Second, in this study, as well as in studies conducted by Ziegler et al. (2008) and Stoeger et al. (2008), the investigations considered solely fourth-grade schoolchildren. In other words, the investigations were conducted with subjects for whom the asymptote for the automation of the writing process had not yet been reached. In future research, care should be taken to determine whether deficits in fine motor skills can still differentiate between achievers and underachievers among more advanced age groups. Attempts should also be made to clarify how the correlations found in our study materialize among younger children. On the basis of these results, appropriate support measures can be conceptualized separately for all age groups. Third, this study investigated solely the relationship between fine motor skills and persistence. It would be of great interest should future research be able to clarify whether similar relationships can be confirmed for further explanatory variables. The potential effects on ability self-concepts were already referred to above. Fourth, the relationships between the variables that contribute to the explanation of the phenomenon of underachievement should be analysed. This could help prevent one from adopting inappropriate educational measures. Let us assume that the differences in test anxiety, which can be traced as the cause for achievement differences between achievers and underachievers, are primarily due to parental attitudes and the home learning environment. In this case, one would focus primarily on encouraging a positive learning environment at home. Should, however, test anxiety and family-based issues prove to have an additive influence, then promotional concepts would want to address these two variables in similar manners.

\section{Funding}

This research received no specific grant from any funding agency in the public, commercial or notfor-profit sectors.

\section{References}

Ackerman PL (1987) Individual differences in skill learning: An integration of psychometric and information processing perspectives. Psychological Bulletin 102: 3-27.

Ackerman PL (1992) Predicting individual differences in complex skill acquisition: Dynamics of ability determinants. Journal of Applied Psychology 77: 598-614.

Baedke D (1980) Handgeschicklichkeit im Kindesalter [Manual dexterity in childhood]. Inaugural dissertation, Marburg, Germany.

Beilei L, Lei L, Qi D, et al. (2002) The development of fine motors and their relations to children's academic achievement. Acta Psychologica Sinica 34: 494-499.

Brickenkamp R (1962) Aufmerksamkeits-Belastungs-Test (Test d2) [The d2 Test - A Timed Test of Selective Attention]. Göttingen, Germany: Hogrefe.

Briggs LJ (1980) Thirty years of instructional design: One man's experience. Educational-Technology 20(2): 45-50.

Cantell MH, Smyth MM and Ahonen TP (1994) Clumsiness in adolescence: Educational, motor, and social outcomes of motor delay detected at 5 years. Adapted Physical Activity Quarterly 11: $115-129$.

Cattell RB (1960) Culture Fair Intelligence Test, Scale 2 (Handbuch. 3. Auflage). Champaign, IL: IPAT. 
Chase CI (1986) Essay test scoring: Interaction of relevant variables. Journal of Educational Measurement 23(1): 33-41.

Christensen CA (2004) Relationship between orthographic-motor integration and computer use for the production of creative and well-structured written text. British Journal of Educational Psychology 74: 551-564.

Christensen CA (2005) The role of orthographic-motor integration in the production of creative and well-structured written text for students in secondary school. Journal of Educational Psychology 5: 441-453.

Ditton H (1998) Studieninteresse, kognitive fähigkeiten und studienerfolg [Interest in college education, cognitive ability, and academic achievement]. In: Abel J and Tarnai C (eds) Pädagogisch-psychologische Interessenforschung in Studium und Beruf. Münster, Germany: Waxmann, pp. 45-61.

Fraser BJ, Walberg HJ, Welch WW, et al. (1987) Syntheses of educational productivity research. International Journal of Educational Research 11: 145-252.

Gordon EW and Bridglall BL (2005) Nurturing talent in gifted students of color. In: Sternberg RJ (ed) Conceptions of Giftedness. 2nd ed. New York: Cambridge University Press, pp. 120-146.

Graham S (1990) The role of production factors in learning disabled students' composition. Journal of Educational Psychology 82: 781-791.

Graham S and Weintraub N (1996) A review of handwriting research: Progress and prospects from 1980-1994. Educational Psychology Review 8: 7-87.

Hughes DC, Keeling B and Tuck BF (1983) Are untidy essays marked down by graders with neat handwriting? New Zealand Journal of Educational Studies 18(2): 184-186.

Kühn R (1987) Welche vorhersage des schulerfolgs ermöglichen intelligenztests? Eine analyse gebräuchlicher verfahren [Prediction of academic achievement by means of intelligence measures. An analysis of tests in use]. In: Horn R, Ingenkamp K and Jäger RS (eds) Tests und Trends 6: Jahrbuch der Pädagogischen Diagnostik Munich: PVU, pp. 26-64.

Losse A, Henderson SE, Elliman D, et al. (1991) Clumsiness in children - do they grow out of it? A 10 year follow-up study. Developmental Medicine and Child Neurology 33: 55-68.

Luo Z, Jose PE, Huntsinger CS, et al. (2007) Fine motor skills and mathematics achievement in East Asian American and European American kindergartners and first graders. British Journal of Developmental Psychology 25: 595-614.

McCoach DB and Siegle D (2003) Factors that differentiate underachieving gifted students from high-achieving gifted students. Gifted Child Quarterly 47: 144-154.

Peters WA, Grager-Loidl H and Supplee P (2000) Underachievement in gifted children and adolescents: Theory and practice. In: Heller KA, Mönks FJ, Sternberg R and Subotnik R (eds) International Handbook of Giftedness and Talent. Oxford: Pergamon.

Phillipson SN (2008) The optimal achievement model and underachievement in Hong Kong: An application of the Rasch model. Psychology Science 50: 147-172.

Piek JP, Baynam GB and Barrett NC (2006) The relationship between fine and gross motor ability, self-perceptions and self-worth in children and adolescents. Human Movement Science 25: 65-75.

Plomin R (1994) Genetics and Experience. The Interplay Between Nature and Nurture. Thousand Oaks, CA: Sage.

Reis SM and McCoach DB (2000) The underachievement of gifted students: What do we know and where do we go? Gifted Child Quarterly 44: 152-170. 
Rimm SB (2003) Underachievement: A national epidemic. In: Colangelo N and Davis GA (eds) Handbook of Gifted Education. New York: Allyn \& Bacon.

Ryneri LJ, Gerber BL and Wiley LP (2003) Gifted achievers and gifted underachievers: The impact of learning style preferences in the classroom. Journal of Secondary Gifted Education 14: 197-204.

Scardamalia M, Bereiter C and Goleman H (1982) The role of production factors in writing ability. In: Nystrand M (ed.) What Writers Know: The Language, Process and Structure of Written Discourse. New York: Academic Press, pp. 173-210.

Scarr S and McCartney K (1983) How people make their own environments: A theory of genotype-environment effects. Child Development 54: 424-435.

Sovik N, Frostad P and Lie A (1994) Can discrepancies between IQ and basic skills be explained by learning strategies? British Journal of Educational Psychology 64: 389-405.

Stoeger H, Ziegler A and Martzog P (2008) Deficits in fine motor skill as an important factor in the identification of gifted underachievers in primary school. Psychology Science 50: 134-146.

Sweedler-Brown CO (1992) The effect of training on the appearance bias of holistic essay graders. Journal of Research and Development in Education 26: 24-29.

Vacc NA, Vacc NN and Fogleman MS (1987) Preschool screening: Using the DIAL as a predictor of first-grade performance. Journal of School Psychology 25: 45-51.

Voelcker-Rehage C (2005) Der zusammenhang zwischen motorischer und kognitiver entwicklung im frühen kindesalter - Ein teilergebnis der MODALIS-studie [The relationship between motoric and cognitive development in early childhood - A partial result from the MODALIS Study]. Deutsche Zeitschrift für Sportmedizin 56: 358-359.

Wang MC, Haertel GD and Walberg HJ (1993) Toward a knowledge base for school learning. Review of Educational Research 63: 249-294.

Wassenberg R, Feron JM, Kessels GH, et al. (2005) Relation between cognitive and motor performance in 5- to 6-year-old children: results from a large-scale cross-sectional study. Child Development 76: 1092-1103.

Weiss RH (2006) Grundintelligenztest Skala 2. CFT 20-R. Handanweisung (3., verbesserte und erweiterte auflage) [Culture Fair Intelligence Test revised, Scale 2]. Goettingen, Germany: Hogrefe.

Ziegler A and Perleth C (1997) Schafft es sisyphos, den stein den berg hinaufzurollen? Eine kritische bestandsaufnahme der diagnose- und fördermöglichkeiten von begabten in der beruflichen erstaus- und weiterbildung vor dem hintergrund des Münchner Begabungsmodells, [Will Sisyphos succeed in rolling the boulder up the hill? A critical assessment of the diagnostic and promotional opportunities available to the gifted in vocational training against the background of the Munich Model of Talent and Giftedness]. Psychologie in Erziehung und Unterricht 44(2): 152-163.

Ziegler A and Stoeger H (2004) Test anxiety among gifted students: causes, indications, and educational interventions for teachers and parents. Journal of the Gifted and Talented Education Council 17: 29-42.

Ziegler A, Stöger H and Martzog P (2008) Feinmotorische Defizite als Ursache des Underachievements begabter Grundschüler [Deficits in fine motor skill causing underachievement of gifted students in primary school]. Diskurs Kindheits- und Jugendforschung 3: 53-66. 


\section{Biographies}

Heidrun Stoeger (PhD) is a full professor of Education at the University of Regensburg, Germany. She holds the chair for School Research, School Development, and Evaluation. She is editor-in-chief of the journal High Ability Studies and a member of the editorial board of the German journal Talent Development. Her main research interests are giftedness, self-regulated learning, motivation and gender.

Albert Ziegler (PhD) is a full professor of Educational Psychology at the FriedrichAlexander-University of Erlangen-Nürnberg, Germany. He is head of the national research and counselling centre for the gifted and editor-in-chief of the journal Talent Development and Excellence. He is Secretary General of the International Research Association for Talent Development and Excellence (IRATDE). His main research interests are the Actiotope model of giftedness, expertise and motivation. 